\title{
Thermal enhancement of windows performance by means of innovative technologies.
}

\author{
Alessandro Cannavale ${ }^{1,2 *}$, Francesco Carlucci $^{3}$, Francesco Fiorito ${ }^{3}$, Francesco \\ Martellotta ${ }^{1}$, Ubaldo Ayr ${ }^{1}$, Umberto Berardi ${ }^{1}$. \\ ${ }^{1}$ Department of Sciences in Civil Engineering and Architecture, Polytechnic University of Bari, \\ 70125 Bari, Italy. \\ ${ }^{2}$ National Research Council, Institute of Nanotechnology (CNR-NANOTEC), Via Monteroni 73100, \\ Lecce, Italy. \\ ${ }^{3}$ Department of Civil, Environmental, Land, Building Engineering and Chemistry, Polytechnic \\ University of Bari, 70125 Bari, Italy.
}

\begin{abstract}
Thermal performances of window frames and glazing represent a field of growing research efforts - worldwide - aiming to reduce energy consumption and achieve indoor comfort. A combination of newly designed super-insulated window frames and innovative glazing technologies may enhance the performance of windows. Aerogel-based "thermal breaks" for window frames, coupled with high-performing glazing, may lead to significant energy saving. In this work, yearly energy use for heating and cooling were assessed in several locations, for building models equipped with innovative technologies, for glazing and frames. The results of numerical simulations confirmed the opportunities offered by new technologies.
\end{abstract}

\section{Introduction}

In recent years, the issue of energy consumption in the construction sector has become increasingly important, due to its effects on global warming, resulting from anthropogenic action. The European Directive 2018/844 states building stock generates $36 \%$ of greenhouse gas emissions, and that almost $50 \%$ of the EU final energy consumption is spent for heating and cooling [1]. One of the most effective ways to reduce the energy consumption of buildings is to improve the thermal characteristics of the building envelope [2]. It has been observed that the increase in the thermal resistance of the external surfaces, if on the one hand translates into a drastic reduction in consumption for heating in winter, may, on the other hand, reduce the dissipation of thermal energy at night, during summer [3]. The reduction of thermal loads for summer air conditioning takes place mainly by means of traditional shielding systems [4] or systems based on chromogenic materials $[5,6]$, as well as forced and natural ventilation [7]. At the window level, it is possible to intervene both on the fixed and mobile frames and on the properties of glazing. Cuce et al. investigated the increasing requirement for highly thermal resistive windows [8]. The thermal characteristics of the frame and the glass panel have been improved, in the state of the art, following several approaches. In some cases, the glazed component has been improved, from a thermal point of view, by inserting super-insulating materials (for instance, granular or monolithic Aerogel 
$[9,10])$ or by means of vacuum insulating panels [11]. Aguilar et al. proposed vacuum glazing, studied by means of the Heat Flux Meter method (ISO 9869-1) [12]. In other cases, some efforts aimed at improving the characteristics of the frame nodes, with the interposition of super-insulating materials, achieving a significant improvement in the thermal performance of the frame. Several research activities have demonstrated that granular Aerogel may drastically reduce the heat loss in buildings. A work by Gao et al. [13] reported energy savings by $21 \%$, using glazing units containing granules of silica aerogel, filling the air gaps. Moretti and Buratti compared monolithic Aerogel glass panes and conventional glazing systems were also compared, showing a $55 \%$ cut in heat losses [14]. In a recent work, an aerogel blanket was inserted in the air chambers of a PVC window frame, leading to a fair reduction in the frame conductance (from 1.06 to $0.92 \mathrm{~W} / \mathrm{m}^{2} \cdot \mathrm{K}$ ) [15]. Some of the authors have recently reported an innovative frame, designed for windows with three glass panes. Cabot Enova IC3100 granular Aerogel was inserted between the external aluminium frame and the internal wooden frame, to create a sort of super-insulating "thermal break" [16]. In such a way, the transmittance of the window frame $\left(\mathrm{U}_{\mathrm{f}}\right)$ was reduced from 3.5 to $0.66 \mathrm{~W} / \mathrm{m}^{2} \cdot \mathrm{K}$. Such windows allowed for a reduction of yearly energy consumption by $27 \%$ and $6 \%$, compared with buildings equipped with single pane windows and standard compliant windows, respectively.

A further approach consists in controlling the thermal properties of a façade element using insulators with switchable properties, so as to modify the thermal resistance according to the air conditioning needs, in different seasons, and thus achieve the right level of thermal comfort. To change the thermal conductance of a glazed system, it is possible to intervene on one of the heat transmission mechanisms, through the glazed component of the fixtures: thermal convection. A similar method was demonstrated, for the first time, by Pflug et al. [17], in 2017. The façade element presented, in fact, can work through two "thermal states": a state defined as insulating, in which the translucent panel made of Basotect (BASF), placed inside the double glazing, it is in a high position, preventing convection through the two cavities generated between the panel and the two external glass sheets; a conductive state, in which the panel is located at a median height, in the air gap, so as to create two openings, one at the top and one at the base. In this way, a spontaneous convection is activated around the panel, activated by the difference in density between the two vertical air columns thus generated, (an internal one and an external one). The authors also report the experimental studies conducted, which made it possible to verify a change in the thermal transmittance $\mathrm{U}$ of the prototype from $1.44 \mathrm{~W} / \mathrm{m}^{2} \cdot \mathrm{K}$ in the "isolant" state to $1.86 \mathrm{~W} / \mathrm{m}^{2} \cdot \mathrm{K}$ in the "conductive" state, in a given configuration. In this work, numerical simulations in dynamic regime were used to assess the energy benefits obtainable using the two technologies mentioned - superinsulation of the frame and switchable thermal insulation of the transparent component - in different climatic contexts, in order to verify their effectiveness (Figure 1). 

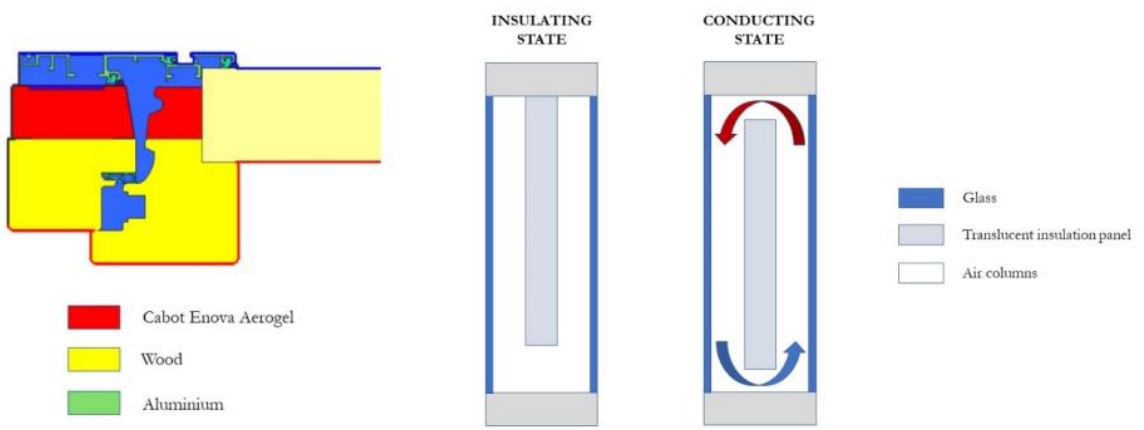

Fig. 1. Super-insulated frame and glazing with switchable U-value.

\section{Methods}

The benefits of high insulated window with variable thermal transmittance were investigated conducting energy analyses with EnergyPlus v.9.4. This choice allowed to properly model responsive envelopes and allowed to use the validated U.S. Department Of Energy (DOE) reference models which can be considered a reliable starting point for energy efficiency oriented researches [18]. In particular, a medium office model was considered for this study, whose characteristics are described in Table 1.

Table 1. Main characteristics of the medium office reference building from DOE.

\begin{tabular}{ccccccc}
\hline $\begin{array}{c}\text { Building } \\
\text { types }\end{array}$ & $\begin{array}{c}\text { Number of } \\
\text { Floors } \\
{[-]}\end{array}$ & $\begin{array}{c}\text { Gross } \\
\text { floor area } \\
{\left[\mathbf{m}^{2}\right]}\end{array}$ & $\begin{array}{c}\text { Floor-to- } \\
\text { floor } \\
\text { height } \\
{[\mathbf{m}]}\end{array}$ & $\begin{array}{c}\text { Floor-to- } \\
\text { ceiling } \\
\text { height } \\
{[\mathbf{m}]}\end{array}$ & $\begin{array}{c}\text { WWR } \\
{[\%]}\end{array}$ & $\begin{array}{c}\text { Number of } \\
\text { thermal } \\
\text { zones } \\
{[-]}\end{array}$ \\
\hline $\begin{array}{c}\text { Medium } \\
\text { Office }\end{array}$ & 3 & 4982 & 3.96 & 2.74 & $33 \%$ & $\begin{array}{c}6 \text { per floor } \\
\text { (5 zones }+ \\
1 \text { plenum) }\end{array}$ \\
\hline
\end{tabular}

In order to understand the behaviour of this new technology, 5 locations with significantly different climates were selected and a reference model was created for each city as summed up in the following table (Table 2).

Table 2. Locations and opaque envelopes characteristics.

\begin{tabular}{lccccc}
\hline & & & \multicolumn{3}{c}{ U-values for opaque envelopes } \\
City & $\begin{array}{c}\text { Köppen-Geiger } \\
\text { classification }\end{array}$ & $\left.\mathrm{HDD}_{18^{\circ} \mathrm{C}} \mathrm{K}\right]$ & \multicolumn{3}{c}{} \\
\cline { 4 - 6 } & & & Ext. wall & Slab & Roof \\
\hline Larnaca (Cyprus) & Bsh & 759 & 0.43 & 0.44 & 0.35 \\
Brindisi (Italy) & Csa & 1151 & 0.34 & 0.38 & 0.33 \\
Madrid (Spain) & Csa & 1965 & 0.29 & 0.29 & 0.26
\end{tabular}




\begin{tabular}{lccccc} 
Paris (France) & $\mathrm{Cfb}$ & 2644 & 0.26 & 0.26 & 0.22 \\
$\begin{array}{l}\text { Copenhagen } \\
\text { (Denmark) }\end{array}$ & $\mathrm{Dfb}$ & 3563 & 0.24 & 0.20 & 0.24 \\
\begin{tabular}{l} 
Reykjavik (Iceland) \\
\hline
\end{tabular} & $\mathrm{Dfc}$ & 4917 & 0.17 & 0.10 & 0.09 \\
\hline
\end{tabular}

Regarding the transparent envelope of the reference model, the thermal transmittance $\left(\mathrm{U}_{\mathrm{w}}\right.$ ref) of the window was calculated in accordance with the technical law UNI EN ISO 10077$1: 2018$, considering a window $90 \mathrm{~cm}$ wide and 130 high composed by a standard insulated frame $\left(\mathrm{Uf}_{\text {ref }}=1.3 \mathrm{~W} / \mathrm{m}^{2} \mathrm{~K}\right)$, a thermal break spacer $(\psi=0.047 \mathrm{~W} / \mathrm{mK})$ and different static glazing system in accordance with the different location and climatic requirements $(0.5 \leq$ $\left.\mathrm{Ug} \leq 2.3 \mathrm{~W} / \mathrm{m}^{2} \mathrm{~K}\right)$. Hence, the resulting window thermal transmittances $\mathrm{U}_{\mathrm{w}}$ ref range between $0.83 \mathrm{~W} / \mathrm{m}^{2} \mathrm{~K}$ and $2.22 \mathrm{~W} / \mathrm{m}^{2} \mathrm{~K}$ as described in Table 2 .

Starting from this reference window, the responsive super insulated and variable $\mathrm{U}$ window was then modelled substituting the standard insulated frame $\left(\mathrm{Uf}_{\text {ref }}=1.3 \mathrm{~W} / \mathrm{m}^{2} \mathrm{~K}\right)$, with the super insulated frame $\left(\mathrm{Uf}_{\text {resp }}=0.66 \mathrm{~W} / \mathrm{m}^{2} \mathrm{~K}\right)$ and considering the same glazing system and spacer. To account for the $U$ variability, starting from the conductive state thermal transmittance ( $\mathrm{U}_{\text {Cond }}$ ), a decrease by $0.42 \mathrm{~W} / \mathrm{m}^{2} \mathrm{~K}$ was considered for the insulating state of the window $\left(\mathrm{U}_{\text {Ins }}\right)$ in accordance with the experimental measurements conducted by Pflug et al. [17]. The resulting characteristic of the glazed surfaces of the reference and responsive models are described in Table 3. All the windows (both in the reference model and in the responsive model) were designed in order to have the same value of SHGC (0.15) and VLT (0.10). The geometric characteristics of modifiable thermal transmittance glass can be found in [17].

Table 3. Locations and reference model characteristics.

\begin{tabular}{lccc}
\hline & $\begin{array}{c}\text { Reference } \\
\text { model }\end{array}$ & \multicolumn{2}{c}{ Responsive model } \\
\cline { 2 - 4 } City & $\begin{array}{c}\mathrm{U}_{\mathrm{w} \text { ref }} \\
{\left[\mathrm{W} / \mathrm{m}^{2} \mathrm{~K}\right]}\end{array}$ & $\begin{array}{c}\mathrm{U}_{\mathrm{w} \text { Cond }} \\
{\left[\mathrm{W} / \mathrm{m}^{2} \mathrm{~K}\right]}\end{array}$ & $\begin{array}{c}\mathrm{U}_{\mathrm{w} \text { Ins }} \\
{\left[\mathrm{W} / \mathrm{m}^{2} \mathrm{~K}\right]}\end{array}$ \\
\hline Larnaca (Cyprus) & 2.22 & 2.07 & 1.65 \\
Brindisi (Italy) & 2.22 & 2.07 & 1.65 \\
Madrid (Spain) & 1.83 & 1.68 & 1.26 \\
Paris (France) & 1.43 & 1.14 & 0.72 \\
Copenhagen (Denmark) & 1.06 & 0.91 & 0.49 \\
Reykjavik (Iceland) & 0.83 & 0.68 & 0.26 \\
\hline
\end{tabular}

To reduce the possible overheating phenomenon caused by a super insulated window, the variable $U$ window state was related to the cooling system and the outdoor air temperature. In particular, the window switches from the insulating to the conductive state when the indoor air temperature exceeds the cooling setpoint $\left(24^{\circ} \mathrm{C}\right)$ and the outdoor air temperature is lower than the indoor temperature. This behaviour allows to foster the heat exchanges through the glazed envelope when these losses help to reduce the cooling loads. To this end, a proper Energy Management System (EMS) program was developed and validated to control the window state. Running the models in five different climates could introduce results variation related to the systems sizing process; therefore, particular attention was 
paid to the independency of results from the HVAC system. To that end, the real HVAC systems were substituted with properly calibrated ideal loads air systems. Ideal loads systems occupy the same hierarchical place of a HVAC unit in EnergyPlus but are not connected to a central system but each ideal system supplies heating or cooling in order to satisfy the zone setpoint [18]. Then, considering average values for packaged direct expansion air conditioning system, the results obtained were divided by an ideal EER equal to 3 in cooling mode and by a COP equal to 3 in heating mode to obtain the electrical energy consumptions. To guarantee the right reliability of these systems and to adapt the ideal loads air system to the existing articulated HVAC system, a calibration of the model was realized implementing an EMS program, in order to properly simulate the multizone air distribution system of the office model. Finally, regarding the ideal loads settings, heating and cooling setpoints of both reference and responsive models were set respectively to $21^{\circ} \mathrm{C}$ and $24^{\circ} \mathrm{C}$. Finally, considering the internal gains, occupancy and indoor appliances were left in accordance with the original DOE reference models while the lighting power was set to $4 \mathrm{~W} / \mathrm{m}^{2}$. Therefore, following the ASHRAE Standards [19], indoor appliances consume a maximum of $10.76 \mathrm{~W} / \mathrm{m}^{2}$ with a radiant fraction equal to 0.5 . A maximum occupancy density of 0.054 persons $/ \mathrm{m}^{2}$ was considered in the offices with a metabolic emission rate equal to $120 \mathrm{~W} /$ person.

\section{Results and Discussion}

The analysis of electricity consumption for summer and winter air conditioning, as anticipated, was carried out for different climatic contexts, adopting the characteristics of as many cities, considered representative. The tables below contain the results of the dynamic numerical simulations, with reference to the behaviour of the office building model taken into consideration.

The following Table 4 reports the results obtained in six different climatic contexts referring to six different cities. It shows the consumption for summer cooling and winter heating, as found for the reference building and for the one equipped with the innovative windows at the basis of this study. The table also shows the differences in consumption, for each use and totally, in absolute terms and percentages.

The results obtained for the city of Larnaca (Cyprus) show that, in the Mediterranean climate, the effectiveness of the super-insulated window with switchable U-value is rather negligible. The high percentage change in consumption for heating during the winter season $(-34.3 \%)$ translates into a change in consumption of only $0.11 \mathrm{kWh} / \mathrm{m}^{2}$, due to the low total consumption. These data demonstrate the ineffectiveness of the technology being studied in the Cypriot town. The variation in electricity consumption for cooling is very limited, as expected. Electricity consumption for cooling is very limited, as expected.

The results obtained for the town of Brindisi (Italy) are not very different from those already observed in the case of Larnaca. The amount of energy consumption for winter $\left(0.61 \mathrm{kWh} /\right.$ year $\left.\mathrm{m}^{2}\right)$ and summer $\left(22.88 \mathrm{kWh} /\right.$ year $\left.\mathrm{m}^{2}\right)$ air conditioning are not very different. Equally similar are the differences between the performances associated to the innovative frame under study and those obtained considering the building equipped with the standard compliant windows. Also in this case, the percentage change of $34.6 \%$ observed in the annual consumption for heating is due to the very low value of the absolute energy consumption, equal to $0.61 \mathrm{kWh} /$ year $^{\prime} \mathrm{m}^{2}$. Therefore, even in the climatic conditions associated with the latitude of the Italian city of Brindisi, the technology under investigation does not show any significant benefits. 
Table 4 - Comparison of energy consumption between office buildings equipped with reference windows and super-insulated windows with switchable U-values.

\begin{tabular}{|c|c|c|c|c|c|}
\hline & & $\begin{array}{c}\text { Responsive } \\
\text { window } \\
{\left[\mathrm{kWh} / \text { year } \mathrm{m}^{2}\right]}\end{array}$ & $\begin{array}{c}\text { Reference } \\
\text { window } \\
{\left[\mathrm{kWh} / \text { year } \mathrm{m}^{2}\right]}\end{array}$ & $\begin{array}{c}\text { Difference on } \\
\text { total } \\
\text { consumption [\%] }\end{array}$ & $\begin{array}{c}\text { Difference on } \\
\text { consumption for } \\
\text { each use [\%] }\end{array}$ \\
\hline \multirow{3}{*}{$\begin{array}{l}\text { Larnaca } \\
\text { (Cyprus) }\end{array}$} & Heating & 0.22 & 0.33 & -0.4 & -34.3 \\
\hline & Cooling & 27.57 & 27.62 & -0.2 & -0.2 \\
\hline & Total & 27.78 & 27.95 & -0.6 & \\
\hline \multirow{3}{*}{$\begin{array}{l}\text { Brindisi } \\
\text { (Italy) }\end{array}$} & Heating & 0.61 & 0.93 & -1.4 & -34.6 \\
\hline & Cooling & 22.88 & 22.80 & 0.3 & 0.3 \\
\hline & Total & 23.48 & 23.73 & -1.0 & \\
\hline \multirow{3}{*}{$\begin{array}{l}\text { Madrid } \\
\text { (Spain) }\end{array}$} & Heating & 1.92 & 2.58 & -4.1 & -25.8 \\
\hline & Cooling & 13.54 & 13.55 & -0.1 & -0.1 \\
\hline & Total & 15.46 & 16.13 & -4.2 & \\
\hline \multirow{3}{*}{$\begin{array}{l}\text { Paris } \\
\text { (France) }\end{array}$} & Heating & 3.45 & 4.75 & -10.0 & -27.3 \\
\hline & Cooling & 8.65 & 8.25 & 3.1 & 4.8 \\
\hline & Total & 12.09 & 12.99 & -6.9 & \\
\hline \multirow[t]{3}{*}{$\begin{array}{l}\text { Copenaghen } \\
\text { (Denmark) }\end{array}$} & Heating & 5.32 & 7.14 & -14.9 & -25.5 \\
\hline & Cooling & 5.44 & 5.07 & 3.0 & 7.3 \\
\hline & Total & 10.76 & 12.22 & -11.9 & \\
\hline \multirow{3}{*}{$\begin{array}{l}\text { Reykjavik } \\
\text { (Iceland) }\end{array}$} & Heating & 5.99 & 8.33 & -23.6 & -28.1 \\
\hline & Cooling & 2.04 & 1.59 & 4.5 & 28.3 \\
\hline & Total & 8.02 & 9.92 & -19.1 & \\
\hline
\end{tabular}

Data obtained by carrying out the dynamic simulations in the climatic context of Madrid are slightly different from those previously commented. The percentage reduction in consumption for heating is about one fourth $(-25.8 \%)$, namely from $2.58 \mathrm{kWh} /$ year $\mathrm{m}^{2}$, in the reference case, to $1.92 \mathrm{kWh} /$ year $\mathrm{m}^{2}$ for the building equipped with innovative windows. On the other hand, the change in consumption observed for summer air conditioning, limited to $0.1 \%$, is not significant.

While in the case of Larnaca and Brindisi the difference in annual energy consumption (for heating and summer air conditioning) was limited to $0.6 \%$ and $0.8 \%$ - respectively -, in the case of Madrid a total reduction of $4.2 \%$ is obtained, with a clear prevalence of savings in consumption for heating, which reaches $4.1 \%$ compared to total yearly consumption per unit of surface. The results obtained become particularly interesting, further increasing the latitude of the location under consideration. For example, in the city of Paris, a reduction in total consumption of $6.9 \%$ is achieved. In absolute terms, the difference in consumption for heating reaches a value of $1.3 \mathrm{kWh} /$ year $\mathrm{m}^{2}$. At the same time, consumption for summer air conditioning undergoes an increase of $0.4 \mathrm{kWh} /$ year $\mathrm{m}^{2}$ which, in part, compensates for the benefit observed for the winter season. However, the $27.3 \%$ reduction in energy use for heating is predominant, compared to the simultaneous increase in consumption for cooling $(4.8 \%)$. 
A similar trend is observed in the other two locations taken into consideration, at further higher latitudes: Copenhagen and Reykjavik. In the Danish capital, consumption for winter heating is higher than for summer air conditioning (in the reference case). In fact, they are $7.14 \mathrm{kWh} /$ year $\mathrm{m}^{2}$ and $5.07 \mathrm{kWh} /$ year $^{2} \mathrm{~m}^{2}$, respectively. In all the cases previously studied, however, the consumption of electricity due to summer air conditioning was predominant, due to the climatic characteristics of the site. The reduction of energy consumption for heating, compared to the reference case, equal to $25.5 \%$, allows in this case to assert that the innovative technology may represent a suitable design option, given the amount of energy savings observed, in absolute and percentage terms. For the first time, savings in energy consumed for heating reached a net value of $1.45 \mathrm{kWh} /$ year $\mathrm{m}^{2}$. It should also be noted, on the other hand, that the positive increase in consumption for air conditioning is very low for Copenhagen.

The observations made for Denmark can be repeated, with the necessary differences in terms of absolute and percentage values, for the Icelandic city of Reykjavik. Moreover, the energy saving for heating in winter reaches a percentage and absolute value of $28.1 \%$ and $2.34 \mathrm{kWh} /$ year' $\mathrm{m}^{2}$, respectively. On the other hand, energy consumption for summer air conditioning was quite negligible.

The graph reported in Figure 2 represents a summary of results obtained, with reference to all the locations considered. Histograms report the difference on energy consumption between office buildings equipped with the new window technology and those equipped with windows compliant with local standards. As it can be observed, such differences increase with HDD value: in fact, the higher the HDD of the location considered, the higher was the difference reported for energy use in heating and cooling, with the former exceedingly higher than the latter. Then, passing from Larnaca to Reykjavik, a clear trend is visible, in terms of percentage differences in consumption. On the other hand, the blue and red lines with circles show that the energy use for air conditioning in summer tends to decrease, whereas energy consumption for heating it tends to increase but to a greater extent - expectedly - with latitude. These data support the hypothesis that the presented technology may be suitable for heating-dominated climates.

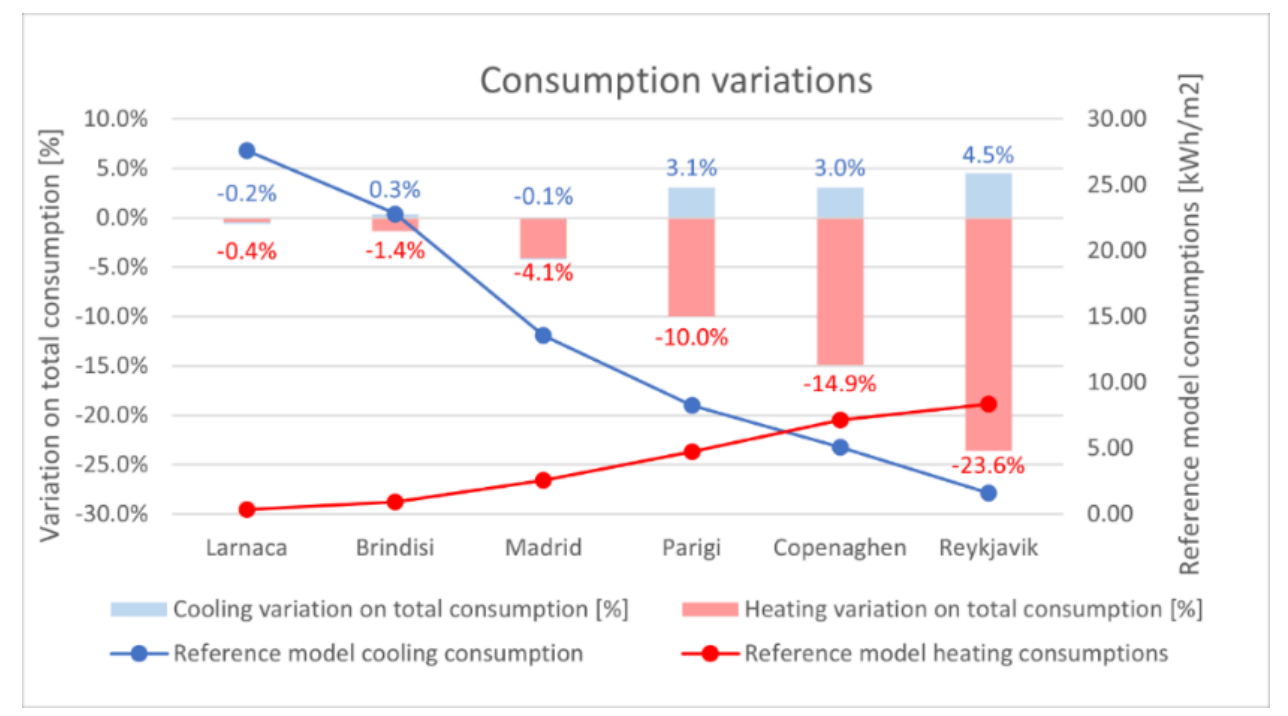

Fig. 2. Variation of energy use (for heating and cooling) in different locations. 
The graphs shown in Figure 3 report the difference in consumption between the building equipped with the innovative technology and the one equipped with standard compliant technology on the ordinate axis and time on the abscissa axis. The daily saving in consumption for air conditioning and heating - respectively - are clearly represented by the blue and red lines. Such differences are very limited in the locations of Larnaca, Brindisi and Madrid, as already noted above. On the contrary, they become significant in the Paris area, where, during the winter season, the proposed technology seems to offer the advantages associated with the super-insulation of the frame. The results obtained for Copenhagen and Reykjavik are very similar to each other: both of them report a relevant increase in benefits associated to the innovative window, which perform slightly better in Iceland, due to the greater extension of the heating period. The results obtained further support the hypothesis according to which the technology under investigation may be advantageous in heating dominated climates.
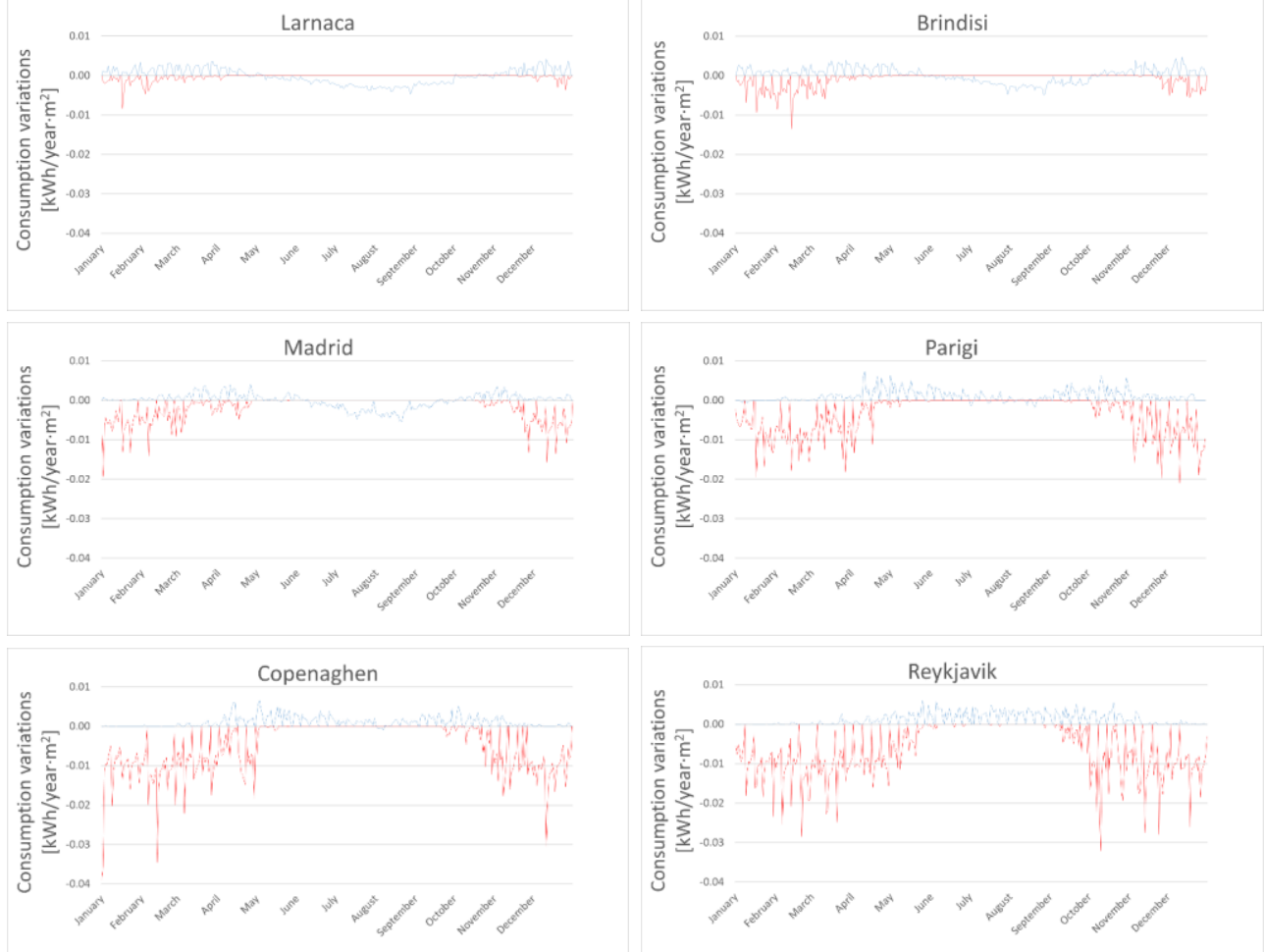

Fig. 3. Variation of energy use for heating (red line) and cooling (blue line) in different locations, on a yearly basis, between the building equipped with innovative windows and the reference one.

Some additional cost considerations for these windows may be helpful. The design of these innovative fixtures requires a threefold level of intervention: 1) the material necessary for the super-insulation of the fixed frame and the mobile frame; 2) the translucent insulating panel to be inserted between the glass panels of the insulating glass unit; 3 ) the movement mechanism of the panel to activate the convective mechanism, in the different seasons of the year. From previous studies, we can report some data that allow us to make some useful reflections. If on the one hand several studies report forecasts according to which the cost of materials such as Aerogel could significantly decrease [16,20], following a significant 
commercial diffusion, on the other it must be said that the use of innovative materials in several components of the window risks making these innovative windows not immediately convenient, with respect to the achievable energy benefits, by increasing the energy payback time of the intervention. Aerogel insulating glazing showed investment payback periods ranging from 7 to 9 years, as reported by Buratti et al. [21]. These considerations show that the proposed technology would not be cost-effective, due to the current cost of materials. However, the study carried out could be interesting in view of future market scenarios or the introduction of cheaper insulation materials.

\section{Conclusions}

This study reports the benefits that can be achieved by using windows equipped with two innovative technologies: a super-insulated frame, based on granular Aerogel and a glass with switchable U-value, that works by activating and deactivating the thermal convection inside the glazed unit. The analysis, carried out by means of numerical simulations in a dynamic regime, made it possible to quantify the achievable energy savings, compared to frame that meets local current regulations. This saving, limited to the winter heating period, becomes significant for locations with HDD higher than 2600, in the Northern hemisphere. In the cities of Paris, Copenhagen and Reykjavik, the percentage energy saving for winter air conditioning reaches $10 \%, 14.9 \%$ and $23.6 \%$, respectively.

\section{References}

[1] EU Parliament, Directive (EU) 2018/844 of the European Parliament and of the Council of 30 May 2018 Amending Directive 2010/31/EU on the Energy

Performance of Buildings and Directive 2012/27/EU on Energy E_ciency, 2018.

[2] B.P. Jelle, A. Hynd, A. Gustavsen, D. Arasteh, H. Goudey, R. Hart, Sol. Energy Mater. Sol. Cells 96, 1-28 (2012).

[3] T. Berger, C. Amann, H. Formayer, A. Korjenic, B. Pospichal, C. Neururer, R. Smutny, J. Build. Eng. 5, 86-95 (2016).

[4] M. Mandalaki, K. Zervas, T. Tsoutsos, A. Vazakas, Sol. Energy 86, 2561-2575 (2012).

[5] A. Cannavale, U. Ayr, F. Fiorito, F. Martellotta, Energies 13, 1-17 (2020).

[6] A. Cannavale, Clean Technol. 2, 462-475 (2020).

[7] S. Yang, F. Fiorito, D. Prasad, A. Sproul, A. Cannavale, J. Build. Eng. 41, 102426 (2021).

[8] E. Cuce, S.B. Riffat, Renew. Sustain. Energy Rev. 41, 695-714 (2015).

[9] U. Berardi, Appl. Energy 154, 603-615 (2015). 
[10] J. Paulos, U. Berardi, Appl. Energy 266, 114776 (2020).

[11] Y. Fang, S. Memon, J. Peng, M. Tyrer, T. Ming, Renew. Energy 150, 167-175 (2020).

[12] J.L. Aguilar-Santana, H. Jarimi, M. Velasco-Carrasco, S. Riffat, Int. J. Low-Carbon Technol. 15, 112-120 (2019).

[13] T. Gao, B.P. Jelle, T. Ihara, A. Gustavsen, Appl. Energy 128, 27-34 (2014).

[14] C. Buratti, E. Moretti, Appl. Energy 97, 430-437 (2012).

[15] D. Valachova, N. Zdrazilova, V. Panovec, I. Skotnicova, Civ. Environ. Eng. 14, $2-$ 11 (2018).

[16] A. Cannavale, F. Martellotta, U. Berardi, C. Rubino, S. Liuzzi, V. De Carlo, U. Ayr, Buildings 10, 60 (2020).

[17] T. Pflug, N. Nestle, T. E. Kuhn, M. Siroux, C. Maurer, Energy Build. 164, 1-13 (2018).

[18] US Department of Energy, US Dep. Energy (2010).

[19] ANSI/ASHRAE/IES, Standard 90.1-2019 - Energy Standard for Buildings Except Low-Rise Residential Buildings, 2019.

[20] E. Cuce, P.M. Cuce, C.J. Wood, S.B. Riffat, Renew. Sustain. Energy Rev. 34, $273-$ 299 (2014).

[21] C. Buratti, E. Belloni, F. Merli, M. Zinzi, Energy Build. 231, 110587 (2021). 